\title{
Aplikasi Kamus Bahasa Indonesia - Palembang Menggunakan Algoritma Interpolation Search Berbasis Android
}

\author{
Yohan Syafri \& R.M Nasrul Halim \\ Universitas Bina Darma \\ Email: Yohan.syafri1305@gmail.com \& Nasrul.halim@binadarma.ac.id
}

\begin{abstract}
A dictionary is a book that has been arranged in alphabetical order, the dictionary that we usually find is complete and good, but lately the use of book dictionaries has become a bit behind because people prefer an easy way to interpret a word, namely using an electronic dictionary. Nowadays, there are many Palembang language dictionary applications based on android, but this application has not changed too much from other similar applications. The author took the initiative to develop this electronic dictionary application so that it looks more attractive and user friendly, this application can later facilitate the communication process between tourists and the people of Palembang City, and can be a place to preserve the Palembang language. In the process of making this mobile application, the author uses an interpolation search algorithm to make it easier to search for sorted data tables or files that have a scalarkey. Data collection techniques that will be used by conducting observations, interviews and using the Mobile-D development method. The result of this researchis an android-based Indonesian-Palembang and Palembang-Indonesian translator dictionary application.
\end{abstract}

Keywords: Palembang, dictionary, interpolation search, mobile-D

\section{Pendahuluan}

Setiap daerah memiliki Bahasa yang berbeda dalam berkomunikasi, untuk dapat memahami Bahasa yang digunakan oleh masing-masing daerah, maka diperlukan suatu alat yang dapat mempermudah menafsirkan kosakata yang ada yaitu kamus, sehingga perbedaan Bahasa tidak menjadi kendala untuk berkomunikasi. Bahasa Palembang, yang secara filologis berintikan ba-hasa Melayu, dan banyak dipengaruhi Bahasa jawa merupakan bahasa Kraton Palembang sejak zaman Kesunanan Palembang.

Penggunaan aplikasi penerjemah berbasis android telah banyak digunakandan dipakai pada telepon pintar. Namun dalam hal ini penulis akan mengembangkan aplikasi penerjemah Bahasa Indonesia Palembang yang sudah ada, dengan menggunakan algoritma interpolation search. algoritma ini menemukan nilai kunci tertentu dalam array indeks yang diurutkan berdasarkan nilai kunci. Ini mirip dengan menampilkan judul dengan nama tertentu, yang merupakan nilai dasar yang digunakan untuk mengurutkan entri dalam buku.Padasetiap tahap pencarian, hitung sisa ruang pencarian tempat kita dapat mencari itemtersebut.Penggunaan algoritma ini sendiri diharapkan dapat menjadikan aplikasi dapat berjalan dengan lebih baik. dalam hal ini penulis berinisiatif untuk mengembangkan aplikasi kamus elektonik 
berbasis android tersebut dengan menambahkan input berbasis suara, agar pengguna nantinya bisa memanfaatkan aplikasi penerjemah dengan lebih maksimal.

Dilihat dari perkembangan teknologi yang telah dijabarkan di atas maka penulis akan mengusulkan membuat aplikasi kamus elektronik Bahasa IndonesiaPalembang dan Palembang-Indonesia, untuk mempermudah wisatawan dalam negeri maupun luar negeri untuk berkomunikasi ketika bedara dalam wilayah Palembang, dimana komunikasi antara 2 orang hanya bisa dilakukan dengan sebuah bahasa jika keduanya memahami bahasa tersebut. Dengan begitu penulis membuat judul: Aplikasi Kamus Bahasa Indonesia - Palembang MenggunakanAlgoritma Interpolation Search Berbasis Android.

\section{Tinjauan Literatur}

Algoritma interpolation search merupakan algoritma untuk pencarian tabeldata yang sudah terurut atau file yang memiiki kunci skalar. Pendekatan pada tabel dilakukan dengan menyisipkan nilai kunci yang dicari dengan batasan nilai dari tabel. Jika elemen yang dicari tidak ditemukan pada posisi yang didekati, maka tabel yang sesuai akan dipilih dan proses penyisipan nilai kunci akan diulangi sampai elemen yang diinginkan telah ditemukan, atau hasil menunjukkan kata dicari tidak ada pada elemen tabel.(Sahara, 2014).

Algoritma interpolation search merupakan algoritma yang dikembangkan dari algoritma binary search, yang mana algoritma binary selalu mencari nilai tengah untuk perbandingan, kemudian membuang sebagian dari space yang tidak mendekati kata yang dicari. Algoritma interpolation search mencoba untuk mencari pendekatan letak kata yang dicari menggunakan linear interpolation (Kukreja,2013).

Penelitian dengan judul Algoritma Sequential Search Dalam Kamus Bahasa Inawatan Berbasis Android yang dilakukan oleh kristia Yuliawan (2021). Penelitian ini memberikan informasi tentang jumlah Bahasa yang ada di Papua danPapua Barat yang berjumlah kurang lebih 414 bahasa dalam kurun waktu 2018- 2019. Salah satu Bahasa yang ada di Papua Barat yaitu Bahasa Inawatan. Penelitian tersebut menggunakan metode Incremental yang terdiri dari requirement, specification, architecture design, code dan test, dan dihasilkanlah sebuah aplikasi kamus Bahasa Inawatan berbasis android.

Penelitian dengan judul Pembuatan Kamus Elektronik Kalimat BasahaIndonesia dan Bahasa Jawa untuk Aplikasi Mobile Menggunakan Interpolation Search yang dilakukan oleh Nur Afifah (2010). Pada penelitian ini telah dibuat software kamus elektronik J2J untuk menerjemahkan kalimat Bahasa Indonesia keBahasa jawa atau sebaliknya. Pembuatan aplikasi ini menggunakan pemrograman J2ME, dan menggunakan metode interpolation search. Hasil dari penelitian yang diperoleh dari pengujian penerjemah kalimat Bahasa Indonesia ke Bahasa jawa untuk jumlah kata sama dengan 5, diperlukan rata-rataa waktu 12,4 milisecond pada emulator, dan 52,8 milisecond pada ponsel. Dari hasil kuisioner didapat data bahwa 100\% responden mengatakan bahwa aplikasi ini bisa dijalankan dimanapun,dan kapanpun 
dengan media perangkat mobile yang praktis

\section{Metode Penelitian}

Penelitian ini penulis menggunakan metode penelitian dan pengembangan (reseach and development). Dengan menggunakan data primer dan sekunder, data perimer didapat melalui wawancara langsung kepada ahli bahasa, sedangkan data sekunder didapat melalui internet dan buku.

Metode pengembangan yang dipakai pada penelitian ini yaitu MetodeMobile-D (Mobile Development). Metode Mobile-D adalah salah satu metode yangcocok untuk pengembangan aplikasi mobile karena bersifat tangkas(agile) dan fleksibel. Mobile-D merupakan pengembangan dari beberapa framework yaitu Extreme Programming, Crystal dan Rationale Unified Process.

Berikut adalah beberapa tahapan metode pengembangan Mobile-D [1]:

\section{Explore}

Tahap ini merupakan tahap untuk menentukan platform yang akan dipakai, pengguna yang akan menggunakan aplikasi, infrastruktur, bahasa pemgrograman, kebutuhan aplikasi.

\section{Initialize}

Melakukan penyiapan sebelum tahap produksi, hal yang harus dilakukan adalah menentukan kebutuhan, product backlog, dan sprint planning.

\section{Productionize}

Tahap pengembangan aplikasi yang terdiri dari 3 tahap, hari perencanaan, hari kerja dan hari rilis aplikasi.

\section{Stabilize}

Pada tahap ini tim pengembang memastikan bahwa aplikasi stabil di perangkat dan sistem operasi.

\section{System Test and Fix}

tujuan dari tahapan ini yaitu melakukan tahap testing sebelum aplikasi dirilis, mulai dari pengujian internal dan pengujian external.

Teknik pengumpulan data yang digunakan dalam penelitian ini menggunakan metode wawancara (interview), Pada tahapan ini dilakukan Teknik pengumpulan data dengan cara tanya jawab dan mewawancarai lansung dengan ahli Bahasa Palembang [2]. Sedangkan pada tahapan Studi Pustaka dan literatur, yang dilakukan pada tahapan ini yaitu pengumpulan informasi untuk mendapatkan data dengan cara membaca dan mempelajari buku-buku, jurnal dan referensi yangberhubungan dengan masalah yang dibahas.

Aplikasi kamus bahasa Indonesia Palembang pada penelitian ini menerapkan algoritma interpolation search, baik pada pencarian kata maupun kalimat, Langkah algoritma interpolation search [3] yaitu:

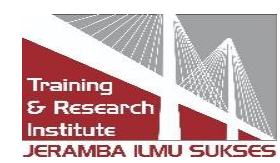


Banyaknya record array $(\mathrm{k})$

Nilai awal $\min =0 ; \max =\mathrm{k}-1$

Hitung $\operatorname{mid}=\min +((k u n c i-k[\min ]) *(\max -\min )) /(k[\max ]-k[\min ])$

Bandingkan data yang dicari(kunci) dengan data posisitengah(mid)

Jika lebih kecil, proses dilanjutkan dengan posisi max = posisitengah-1

Jika lebih besar, proses dilanjutkan dengan posisi min=posisitengah +1

Jika data posisi tengah(mid) = data yang dicari(kunci), makaindex $=$ mid, selesei

Jika $\min <=$ max dan $\mathrm{k}[\mathrm{mid}]=$ !kunci, maka ulangi langkah 3

Jika $\mathrm{k}[\mathrm{mid}]=$ !kunci, maka index $=-1$

Selesai.

\section{Hasil dan Pembahasan}

Tahapan hasil pada metode pengembangan Mobile-D, dalam pembuatan aplikasi kamus bahasa Indonesia Palembang adalah Productionize, Stabilize, system test and fix.

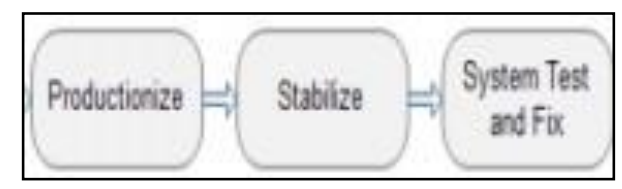

\section{Gambar 1. Tahapan Hasil Metode Mobile-D [4]}

\section{Productionize}

Pada tahapan productionize ini terdapat tiga langkah yaitu:

Planning day

Peneliti menginput data kosakata yang telah didapat ke dalam database aplikasi kamus. Bahasa Palembang Indonesia. 


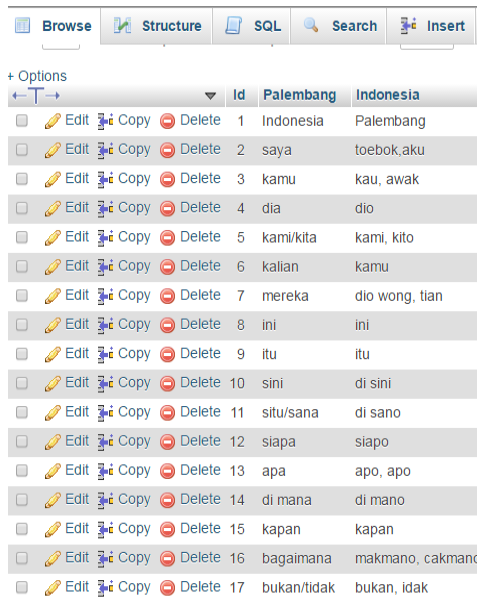

\section{Gambar 2. Input Kosakata Ke Database}

Working day

Peneliti Mencari coding yang sesuai dengan algoritma interpolation search yang telah ditentukan untuk membuat aplikasi kamus Bahasa Indonesia Palembang, Gambar 3. merupakan tampilan coding dari algoritma interpolation search.

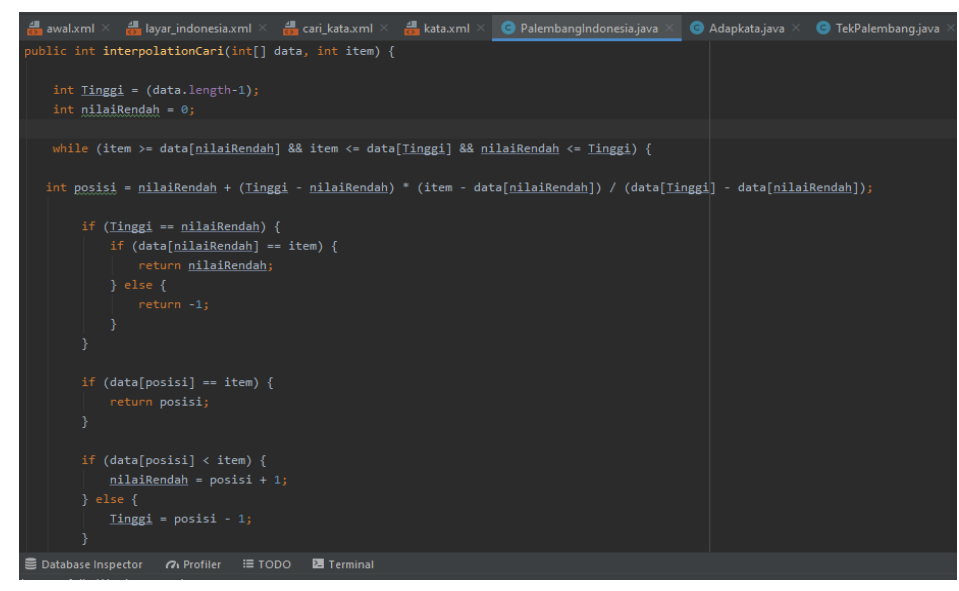

Gambar 3. Coding Algoritma Interpolation Search

Release day

Peneliti menggabungkan coding program yang sudah di uji coba dan melakukan penanganan terhadap kesalahan dalam pembuatan Aplikasi kamusBahasa Indonesia Palembang.

\section{Stabilize}

Tahapan Stabilize ini terdiri dari empat langkah yaitu :

Planning day

Published by:

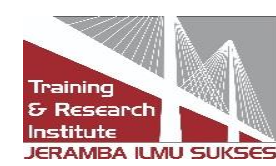


Peneliti melengkapi data data yang akan digunakan, serta melakukan tahapan testing pada coding program.

Working day

Pada tahapan working day ini langkah yang dilakukan yaitu:

Memecahkan masalah yang ada dalam pelaksanaan pembuatan kamus Bahasa Palembang, seperti eror dalam coding maka langsung dilakukan perbaikan.

Awal kegiatan membuat aplikasi kamus Bahasa Palembang Indonesia berbasis android

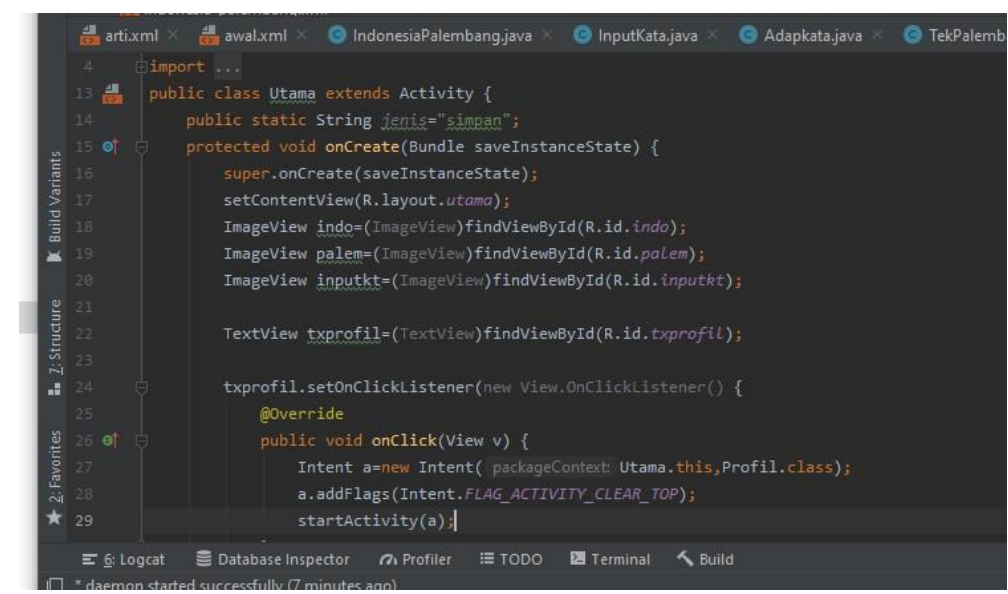

Gambar 4. Coding Program Halaman Awal

Documentation Wrap-up

Pada Langkah ini, peneliti melakukan dokumentasi dalam pembuatan aplikasi kamus Bahasa Indonesia Palembang, berupa Screenshoot dari awal membuka aplikasi sampai menjalankan smartphone.

Realease Day

Peneliti memastikan bahwa aplikasi kamus bahasa Palembang Indonesia Sudah siap untuk digunakan, dan memastikan pembuatan aplikasi ini sudah sesuai dengan rancangan awal.

\section{System Test And Fix}

Pada tahapan ini peneliti melihat apakah aplikasi kamus bahasa Indonesia Palembang menghasilkan fungsi dengan benar dan telah memperbaiki kekurangan yang ditemukan. Tahapan yang dilakukan yaitu:

System Test

Melakukan tes apakah terdapat kesalahan pada aplikasi kamus bahasa Indonesia Pelembang, berikut kasus dan hasil uji coba yangdilakukan. Dibawah ini beberapa pengujian yang dilakukan, yaitu:

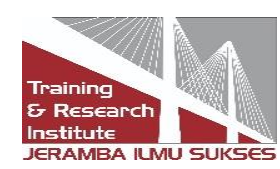


Tabel 1. Pengujian Palembang-Indonesia

\section{KASUS DAN HASIL UJI COBA}

\section{a. Input Data palembang ke Indonesia}

\begin{tabular}{l|l}
\hline Data masukan & Memasukkan kosakata yang akan diterjemahkan \\
\hline Yang diharapkan & Proses memasukkan kosakata yang akan diterjemahkan \\
\hline Pengamatan & Dapat memasukkan kalimat kedalam kolom penerjemah \\
\hline Kesimpulan & {$[\boldsymbol{V}$ ] Berhasil [ ] Tidak berhasil } \\
\hline
\end{tabular}

\section{b. Output Palembang ke Indonesia}

\begin{tabular}{l|l}
\hline Data masukan & Melihat Hasil terjemahan \\
\hline Yang diharapkan & Dapat menampilkan kata yang sesuai dengan terjemahan \\
\hline Pengamatan & aplikasi mengeluarkan terjemahan sesuai dengan kata \\
\hline Kesimpulan & {$[\boldsymbol{v}$ ] Berhasil [ ] Tidak berhasil } \\
\hline
\end{tabular}

\section{c. Input Data Indonesia ke Palembang}

\begin{tabular}{l|l}
\hline Data masukan & Memasukkan kosakata yang akan diterjemahkan \\
\hline Yang diharapkan & Proses memasukkan kosakata yang akan diterjemahkan \\
\hline Pengamatan & Dapat memasukkan kalimat kedalam kolom penerjemah \\
\hline Kesimpulan & {$[\boldsymbol{V}$ ] Berhasil [ ] Tidak berhasil } \\
\hline
\end{tabular}

\section{d. Output Indonesia ke Palembang}

\begin{tabular}{l|l}
\hline Data masukan & Melihat Hasil terjemahan \\
\hline Yang diharapkan & Dapat menampilkan kata yang sesuai dengan terjemahan \\
\hline Pengamatan & aplikasi mengeluarkan terjemahan sesuai dengan kata \\
\hline Kesimpulan & {$[\boldsymbol{\vee}$ ] Berhasil [ ] Tidak berhasil } \\
\hline
\end{tabular}

Tabel 2. Pengujian Tampilan Input kata

\section{KASUS DAN HASIL UJI COBA}




\section{View Input kata}

\begin{tabular}{l|l}
\hline data masukan & Memilih menu Input kata \\
\hline yang diharapkan & menampilkan seluruh list kata \\
\hline pengamatan & dapat mengubah dan menghapus kata \\
\hline kesimpulan & {$[\boldsymbol{V}]$ Berhasil [ ] Tidak berhasil } \\
\hline
\end{tabular}

Tabel 3. Pengujian tampilan simpan kata

\begin{tabular}{l|l}
\hline \multicolumn{2}{c}{ KASUS DAN HASIL UJI COBA } \\
\hline View Simpan kata & Memilih simbol plus diatas list kata \\
\hline data masukan & menampilkan kolom penambah kata \\
\hline yang diharapkan & dapat menyimpan kosakata baru \\
\hline pengamatan & {$[v$ ] Berhasil [ ] Tidak berhasil } \\
\hline kesimpulan &
\end{tabular}

\section{Planning day}

Meningkatkan proses pembuatan aplikasi kamus bahasa Indonesia- Palembang agar sesuai dengan kebutuhan yang dirancang peneliti.

\section{Working Day}

Peneliti melakukan perbaikan sehingga fungsi akan sesuai dengan yangsudah peneliti rancang.

\section{Release Day}

Pada tahapan release day langkah yang dilakukan yaitu:

Mempersiapkan aplikasi kamus bahasa Indonesia - Palembang yang telah dibuat dalam bentuk APK

Mendaftarkan Aplikasi ke Google Play Store 


\begin{tabular}{l|l|lr}
$\mathrm{J}$ & $\mathbf{N}$ & $\begin{array}{l}\text { JURNAL } \\
\text { NASIONAL } \\
\text { ILMU } \\
\text { KOMPUTER }\end{array}$ & $\begin{array}{r}\text { Jurnal Nasional IImu Komputer } \\
\text { e-ISSN: 2746-1343 } \\
\mathrm{K}\end{array}$ \\
\hline
\end{tabular}

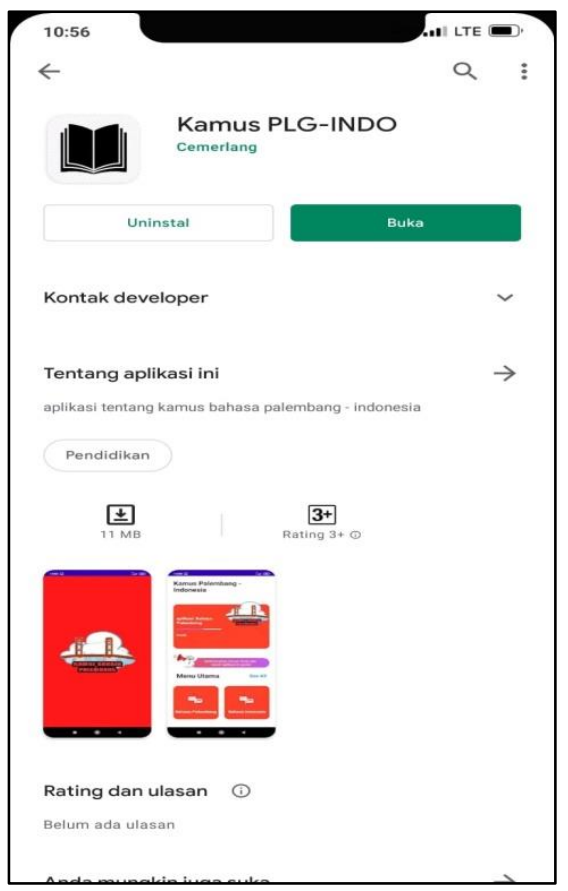

Gambar 5. Rilis aplikasi pada Google Play Store

Aplikasi kamus bahasa Indonesia-palembang berbasisandroid siap digunakan.

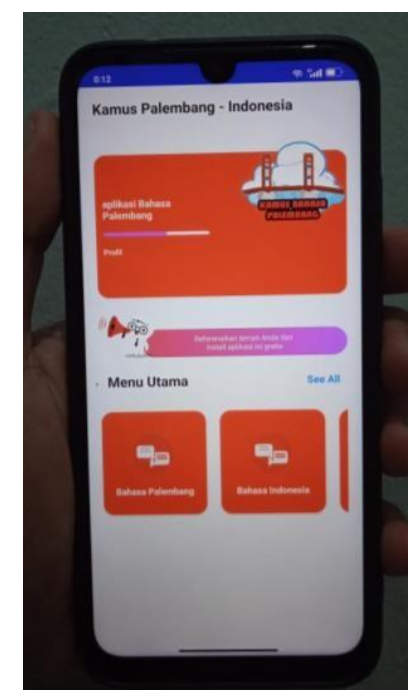

Gambar 6. Aplikasi siap digunakan dan di install di smartphone 


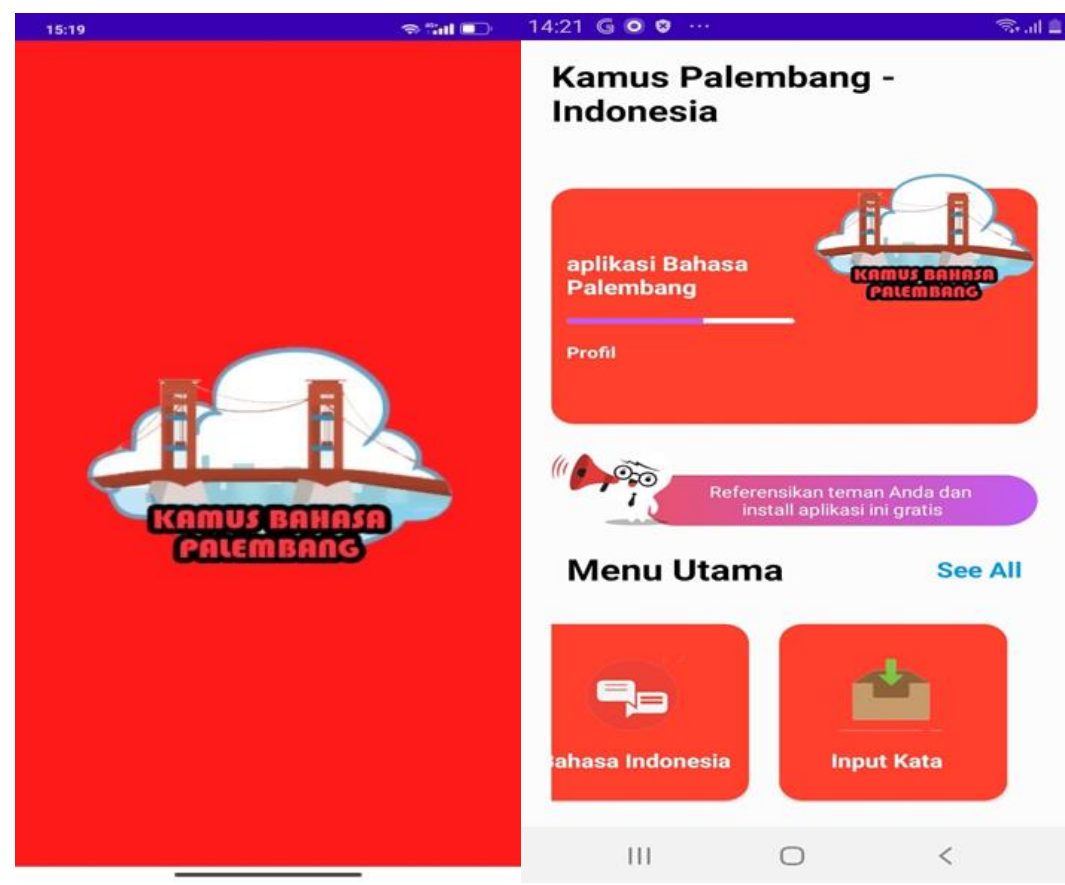

Gambar 7. Tampilan Splash Screen dan Tampilan Halaman Utama

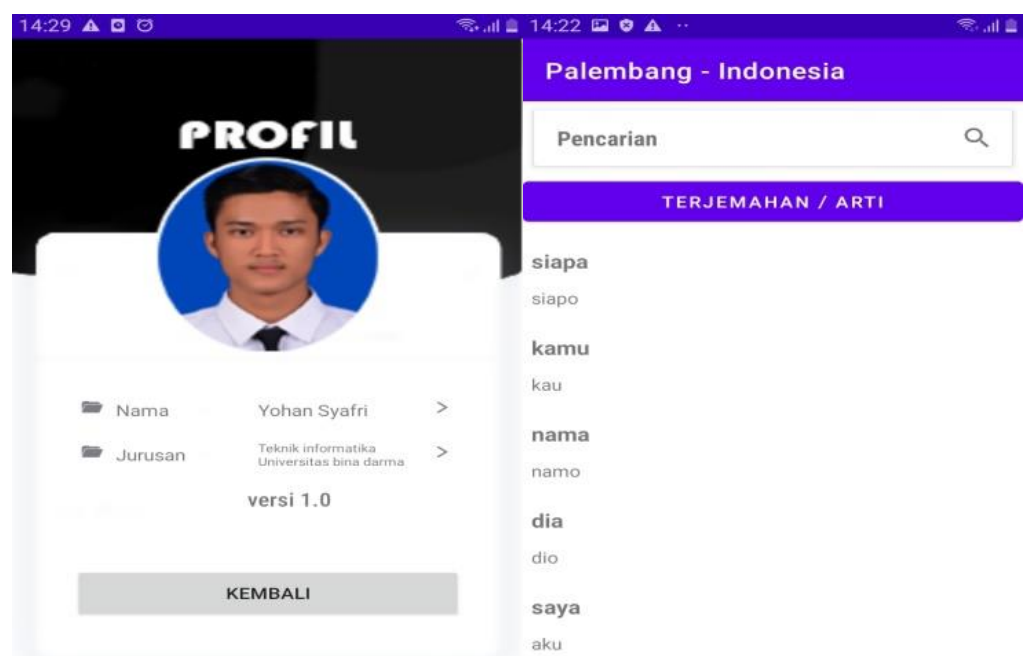

III

○

III

Gambar 8. Tampilan Profil dan Tampilan Pencarian Bahasa Palembang

Published by:

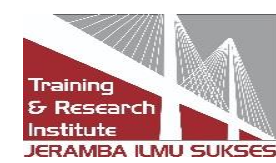




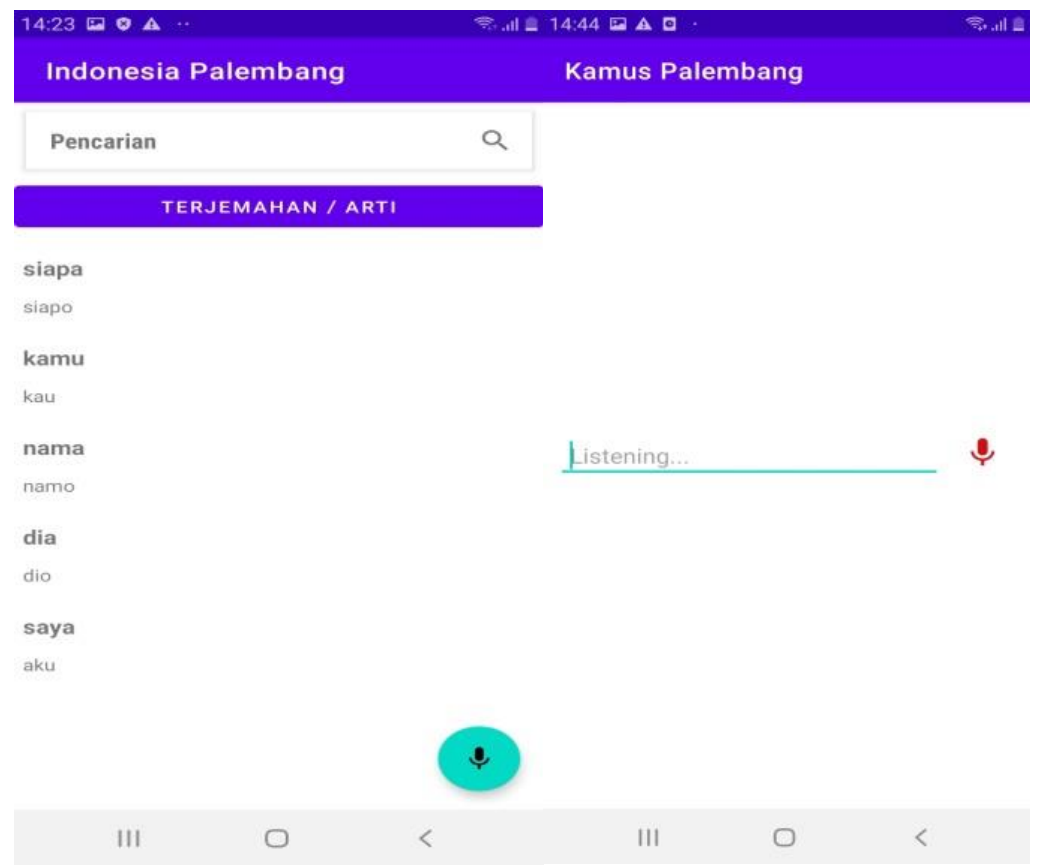

Gambar 9. Tampilan Pencarian dan Tampilan Pencarian Bahasa Indonesia Dengan Suara

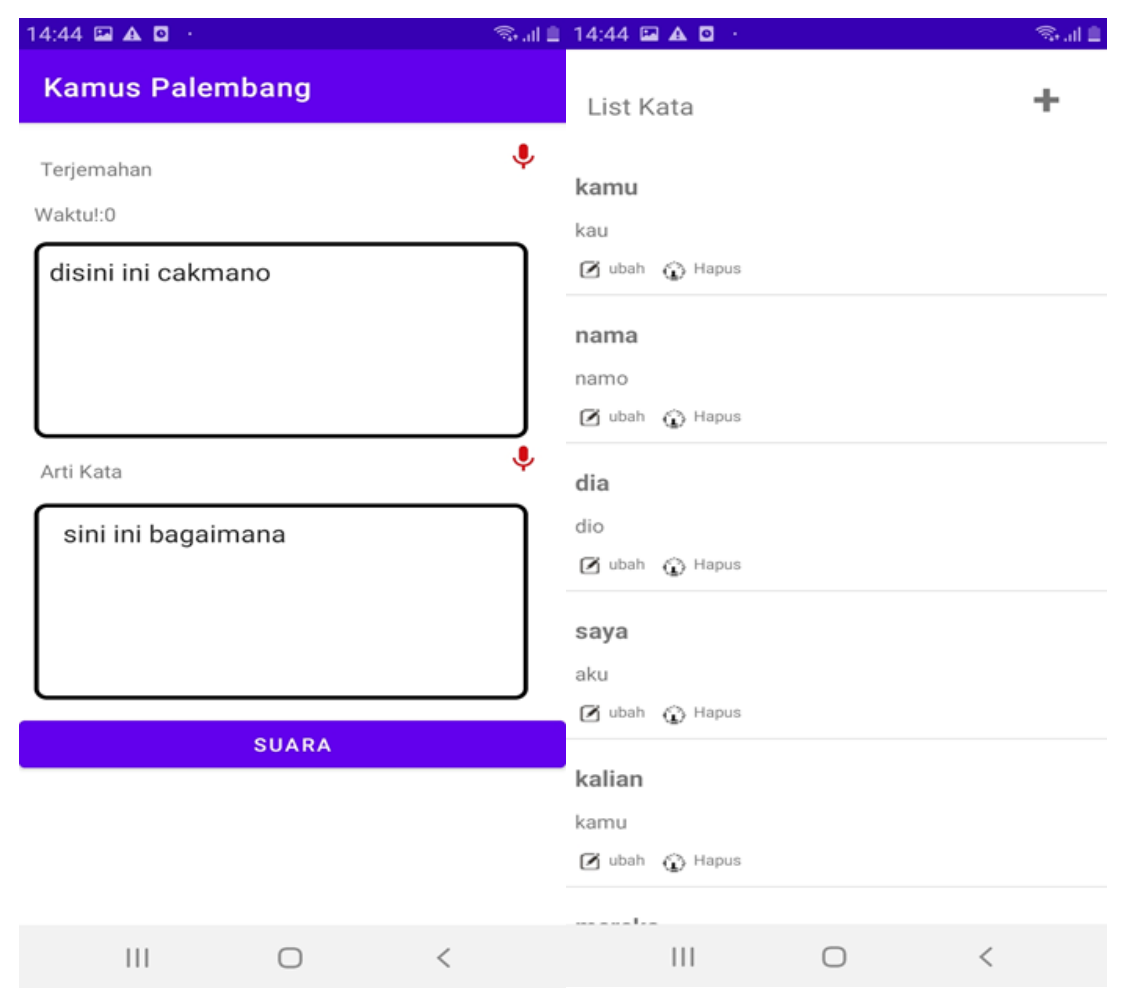

Gambar 10. Tampilan Hasil Tampilan Menu List Kata Pencarian 


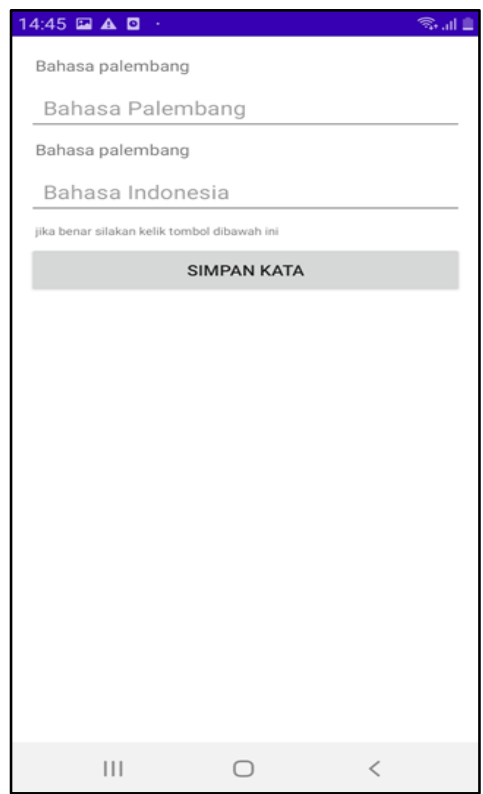

Gambar 11. Tampilan Simpan Kata 


\section{Kesimpulan}

Adapun kesimpulan dari penelitian ini adalah: Penelitian ini menghasilkan sebuah aplikasi berbasis android, yaitu kamus bahasaIndonesia-palembang. Aplikasi kamus Bahasa IndonesiaPelambang ini dibuat dalam bentuk mobile berbasis android yang portable sehingga mudah digunakan pada waktu dan tempat yang diinginkan. Aplikasi kamus Bahasa IndonesiaPelambang ini berjalan menggunakan algoritma interpolation serach, agar mempermudah dalam proses pencarian kata maupun kalimat.

\section{Referensi}

Adyatma, A., \& Nurrohim, A. H. (2011). APLIKASI PENERJEMAH KATA DALAM BAHASA INDONESIA BAHASA INGGRIS DAN BAHASA PALEMBANG BERBASIS JAVA ME.

Afifah, N., Santoso, T. B., \& Yuliana, M. (2010). Pembuatan Kamus Elektronik Kalimat Bahasa Indonesia dan Bahasa Jawa untuk Aplikasi Mobile Menggunakan Interpolation Search. EEPIS Final Project.

Afrie, D. (2016). Rancang Bangun Aplikasi Kamus Obat Hewan Berbasis Android dengan menggunakan Metode Interpolation Search [PhD Thesis]. University of Muhammadiyah Malang.

Amin, B. M., Amin, A. A., Amin, M., \& Tadjuddin, Z. A. M. (2010). Tata Bahasa dan Kamus Baso Palembang (Edisi 2). Yayasan Madrasah Najaniyah.

Annisa, R. (2017). Perancangan Kamus Istilah Akuntansi Berbasis Desktop Dengan Metode Interpolation Search.

Firmansyah, F., Yulianto, A., \& Wigandi, D. P. (2018). Implementasi Mobile-D Dalam Pengembangan Aplikasi Mobile Berbasis Android. SNIT 2018, 1(1), 1-6.

Gunawan, G. (2016). Aplikasi Kamus Istilah Ekonomi (Inggris-Indonesia) Menggunakan Metode Sequential Searching. Pseudocode, 3(2), 122-128.

Juraman, S. R. (2014). Pemanfaatan smartphone android oleh mahasiswa ilmu komunikasi dalam mengakses informasi edukatif. Acta Diurna Komunikasi, 3(1).

Kusniyati, H., \& Sitanggang, N. S. P. (2016). Aplikasi Edukasi Budaya Toba Samosir Berbasis Android. Jurnal Teknik Informatika, 9(1).

Lengkong, H. N., Sinsuw, A. A., \& Lumenta, A. S. (2015). Perancangan penunjuk rute pada kendaraan pribadi menggunakan aplikasi mobile gis berbasis android yang terintegrasi pada google maps. Jurnal Teknik Elektro Dan Komputer, 4(2), 18-25.

Mutakhiroh, I., Saptono, F., Hasanah, N., \& Wiryadinata, R. (2007). Pemanfaatan Metode Heuristik dalam Pencarian Jalur Terpendek dengan Algoritma Semut dan Algoritma Genetika. Seminar Nasional Aplikasi Teknologi Informasi (SNATI).

Pressman, R. S. (2012). Rekayasa perangkat lunak.

Sahara, V. N. (2014). Studi perbandingan dan implementasi algoritma Aho Corasick String Matching dengan algoritma Interpolation Search pada aplikasi kamus kedokteran berbasis mobile [PhD Thesis]. Universitas Islam Negeri Maulana Malik Ibrahim.

Safaat H, Nazruddin. (2012). "Pemrograman Aplikasi Mobile Smartphone dan Tablet PC

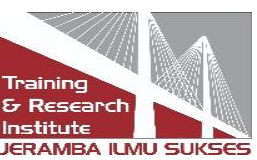


Berbasis Android Edisi Revisi'Bandung:Informatika Bandung

Hansun Seng, Marcel Bonar Kristanda, Michael Wijaya Saputra .(2018). "Pemrograman Android dengan Android Studio IDE 'Yogyakarta:ANDI

Kadir Abdul. (2018). "Pemrograman Android dan Database"Jakarta: PT Elex Media Komputindo

Supriyanto. (2010). "Pemrograman Database Menggunakan Java dan MySQL untuk Pemula"Jakarta Selatan: mediakita

Kumar, C. S., \& Rao, P. M. (2011). Design of an automatic speaker recognition system using MFCC, Vector Quantization and LBG algorithm. International Journal on Computer Science and Engineering, 3(8), 2942.

\section{Copyrights}

Copyright for this article is retained by the author(s), with first publication rights granted to the journal.

This is an open-access article distributed under the terms and conditions of the Creative Commons Attribution license (http://creativecommons.org/licenses/by/4.0/) 